\title{
Phenolic Contents and Antioxidant Potential of Crataegus Fruits Grown in Tunisia as Determined by DPPH, FRAP, and $\beta$-Carotene/Linoleic Acid Assay
}

\author{
Farouk Mraihi, ${ }^{1}$ Mohamed Journi, ${ }^{1}$ Jamila Kalthoum Chérif, ${ }^{1,2}$ Munevver Sokmen, ${ }^{3}$ \\ Atalay Sokmen, ${ }^{4}$ and Malika Trabelsi-Ayadi ${ }^{1}$ \\ ${ }^{1}$ Laboratoire d'Application de la Chimie aux Ressources et Substances et Substances Naturelles et à l'Environnement (LACReSNE), \\ Faculté des Sciences de Bizerte, 7021 Zarzouna, Tunisia \\ ${ }^{2}$ Institut Préparatoire aux Etudes d'Ingénieurs de Tunis (IPEIT), 1008 Tunis, Tunisia \\ ${ }^{3}$ Department of Chemistry, Faculty of Science and Literature, Karadeniz Technical University, 61080 Trabzon, Turkey \\ ${ }^{4}$ Department of Biology, Faculty of Science and Literature, Karadeniz Technical University, 61080 Trabzon, Turkey
}

Correspondence should be addressed to Farouk Mraihi; mraihi_farouk@yahoo.fr

Received 31 May 2013; Revised 25 August 2013; Accepted 3 September 2013

Academic Editor: Souhail Besbes

Copyright (C) 2013 Farouk Mraihi et al. This is an open access article distributed under the Creative Commons Attribution License, which permits unrestricted use, distribution, and reproduction in any medium, provided the original work is properly cited.

\begin{abstract}
Crataegus fruit is one of most important fruits in Tunisian flora. Some fruits of this genus are edible. This study was undertaken in order to examine the benefits of these fruits in human health and their composition of antioxidants including total polyphenol, flavonoids, proanthocyanidins content, and total anthocyanins. The antioxidative properties of the ultrasonic methanolic extract were assessed by different in vitro methods such as the FRAP, DPPH, and $\beta$-carotene/linoleic acid assay. We concluded that peel fraction of red fruits possessed relatively high antioxidant activity and might be a rich source of natural antioxidants in comparison with the pulp and seed fruit extract. The results also showed that hawthorn yellow fruit presents lower amounts of phenolic content, absence of anthocyanins, and less antioxidant capacity. Most of peel and seed fractions were stronger than the pulp fractions in antioxidant activity based on their DPPH IC ${ }_{50}$, FRAP values, and results of $\beta$-carotene/linoleic acid. The total phenolic compounds contents were also highly correlated with the DPPH method and the FRAP assay.
\end{abstract}

\section{Introduction}

Dietary phenolic compounds have received much attention during the recent years due to their antioxidant and other biological properties imparting possible benefits to human health $[1,2]$. Crude extracts of fruits, herbs, and vegetables are rich sources of polyphenols. These compounds include phenolic acids (hydroxybenzoic acids and hydroxycinnamic acids), flavonoids (flavonols, flavones, flavanols, flavanones, isoflavones, anthocyanins, and proanthocyanidins), vitamins, and carotenoids. These bioactive molecules can delay or inhibit the oxidation of lipids and other molecules by inhibiting the initiation or propagation of oxidative chain reactions [3].
Antioxidant activity of phenolic compounds is mainly due to their redox properties, which can play an important role in absorbing and neutralizing free radicals [4]. In order to receive a reliable picture of antioxidants content in Crataegus monogyna and Crataegus azarolus fruits extract, total polyphenols, total flavonoids, proantnocyanidins content, and total anthocyanins content were determined quantitatively using spectrophotometer methods. It was also shown that the measure of antioxidant capacity in natural products by only one assay is often not reliable; therefore, in this investigation, we used three complementary assays such as DPPH radical scavenging assay, ferric-reducing/antioxidant power (FRAP) and $\beta$-carotene linoleic acid assay to check the antioxidant activity of these fruits. 


\section{Materials and Methods}

2.1. Plant Material. Two series of Crataegus azarolus and Crataegus monogyna fruits $(2 \mathrm{~kg}$ ) were collected from Jendouba, north of Tunisia, in September 2011. Fruits were immediately transported to the Department of Chemistry of the Faculty of Sciences in Bizerte. Each fruit was separated into three parts such as peel, pulp, and seed. They were lyophilized and kept in desiccators, and the fresh fruit was stored at $-4^{\circ} \mathrm{C}$ until analysis.

2.2. Chemical Reagents. The chemical reagent Trolox (6hydroxy-2,5,7,8-tetramethylchroman-2-carboxylic acid) was purchased from Aldrich Chemical Co. (Milwaukee, WI). Linoleic acid, BHT, free radical DPPH, and FRAP reagent were from Sigma Co. (St. Louis, MO, USA). Folin-Ciocalteu's reagent and all standard antioxidants were from Fluka Chemie (Buchs, Switzerland). Tween 40 is from Merck. All other chemical reagents used for extract were obtained from Sigma Co. (St. Louis, MO).

2.3. Ultrasound-Assisted Procedures Extraction. The peel, pulp, and seed of red and yellow fruit of Crataegus were processed separately; approximately $2 \mathrm{~g}$ of lyophilized fruit parts was extracted 3 times by $15 \mathrm{~mL}$ of methanol/acidified water $\mathrm{HCl} 1.5 \mathrm{~N}(80 / 20 \mathrm{v} / \mathrm{v})$ during $30 \mathrm{~min}$ in an ultrasonic bath (FALC Instruments, Italy) [5]. The extracts were then washed with hexane to remove chlorophyll and other low molecular weight compounds. The extracts were centrifuged, the solvent was evaporated under reduced pressure, and the residue was dissolved in ultrapure water and lyophilized. The crude extract was kept to quantify the total antioxidant contents.

\section{Determination of Total Antioxidant Compounds}

3.1. Total Phenolic Content. Total phenolic content was quantified using the modified Folin-Ciocalteu's method [6]. FolinCiocalteu's reagent/water $(750 \mu \mathrm{L}, 1: 14)$ mixture was added to a $50 \mu \mathrm{L}$ sample and the reaction was stopped exactly 3 min after adding $200 \mu \mathrm{L}$ of $20 \% \mathrm{Na}_{2} \mathrm{CO}_{3}$. The solution was homogenized, vortexed and heated at $100^{\circ} \mathrm{C}$ for $2 \mathrm{~min}$, and kept in the dark room for $30 \mathrm{~min}$ for incubation. Absorbance was read at $760 \mathrm{~nm}$ using a UV-Vis spectrophotometer T60U. All assays were carried out at least in duplicate and $\mathrm{MeOH}$ was used as blank ( $50 \mu \mathrm{L}$ instead of the extract). Methanolic dilutions of gallic acid were used as standard; results were expressed as gallic acid equivalent per gram of lyophilized sample.

3.2. Total Flavonoid Content. Total flavonoid content was measured using the modified colorimetric method of Zhishen et al. [7]. In sealed tubes, $1.5 \mathrm{~mL}$ of a $2 \%$ methanol solution of $\mathrm{AlCl}_{3} \cdot 6 \mathrm{H}_{2} \mathrm{O}$ was added to $0.5 \mathrm{~mL}$ of sample and then kept in dark for $10 \mathrm{~min}$. Absorbance was read at $430 \mathrm{~nm}$, methanolic $\mathrm{AlCl}_{3}$ was used as blank, and each measure was made in triplicate. A series of methanolic dilutions of rutin were prepared and assayed; flavonoid amounts in extract were expressed in mg rutin equivalent flavonoid/100 g dry matter [8].

3.3. Proanthocyanidin Content. In sealed tubes, $0.5 \mathrm{~mL}$ sample was added to a solution of $0.5 \mathrm{~mL} \mathrm{MeOH}, 6 \mathrm{~mL}$ of $\mathrm{n}$ $\mathrm{BuOH} /$ concentrated $\mathrm{HCl}(95: 5 \mathrm{v} / \mathrm{v})$, and $0.2 \mathrm{~mL}$ of a $2 \%$ $\mathrm{NH}_{4} \mathrm{Fe}\left(\mathrm{SO}_{4}\right)_{2} \cdot 12 \mathrm{H}_{2} \mathrm{O}$ solution in $2 \mathrm{M} \mathrm{HCl}$. Absorbance was read at $550 \mathrm{~nm}$ before and after heating for $40 \mathrm{~min}$ at $95^{\circ} \mathrm{C}$ (each measure in triplicate, blank $\mathrm{n}-\mathrm{BuOH} / \mathrm{HCl}$ mixture). A series of dilutions of cyanidin chloride in $\mathrm{n}-\mathrm{BuOH} / \mathrm{HCl}$ were assayed; proanthocyanidin amounts in extracts were expressed in mg cyanidin/100 g dry matter and were calculated from the following equation [9]:

$$
\begin{aligned}
& \text { PC } \\
& =\left[\frac{\left(A_{550} \text { sample }-A_{550} \text { control }\right)}{(\varepsilon * L)}\right] * \mathrm{MW} * \mathrm{DF} * 1000,
\end{aligned}
$$

where PC is proanthocyanidin contents expressed in $\mathrm{mg}$ cyanidin/100 g dry matter, $A_{550}$ sample is the absorbance of the sample at $550 \mathrm{~nm}, A_{550}$ control is the absorbance of the control at $550 \mathrm{~nm}, \varepsilon=17,360 \mathrm{~L}^{-1} \mathrm{M}^{-1} \mathrm{~cm}^{-1}$ molar absorptivity coefficiency of cyanidin, $L$ is the cell path length $(1 \mathrm{~cm}), \mathrm{MW}=$ molecular weight of cyaniding $\left(287 \mathrm{~g} \mathrm{~mol}^{-1}\right)$, $\mathrm{DF}$ is the dilution factor $\left(\mathrm{g} \mathrm{L}^{-1}\right)$, and 1000 is the factor for conversion from $\mathrm{g}$ to $\mathrm{mg}$.

3.4. Total Monomeric Anthocyanins (TMA). Total anthocyanins were quantified using the $\mathrm{pH}$ differential method described by Giusti and Wrolstad [10]. This method was based on reversible structural transformations of anthocyanin pigments in different $\mathrm{pH}$ solutions using a UV-Vis spectrophotometer (model T60U, PG Instruments). $960 \mu \mathrm{L}$ of $\mathrm{pH} 1(25 \mathrm{~mL}$ of $1.49 \% \mathrm{KCl}+67 \mathrm{~mL}$ of $1.7 \% \mathrm{HCl}, \mathrm{pH}$ corrected with $\mathrm{HCl})$ and $\mathrm{pH} 4.5(1.64 \% \mathrm{AcONa}, \mathrm{pH}$ corrected with $\mathrm{AcOH}$ ) buffer solutions were each added to $40 \mu \mathrm{L}$ of extract. Absorbance was read at 700 and $510 \mathrm{~nm}$ against water as blank. Each measure was made in triplicate. The results were expressed in mg cyanidin-3 glucoside/100 g dry matter:

$$
\begin{aligned}
\mathrm{TACY}= & {\left[\frac{\Delta A \times \mathrm{MW} \times \mathrm{DF} \times 1000}{\varepsilon}\right] \times 0.1, } \\
\Delta A= & {\left[A_{512} \mathrm{~nm}-A_{700} \mathrm{~nm}\right]_{\mathrm{pH} 1.0} } \\
& -\left[A_{512} \mathrm{~nm}-A_{700} \mathrm{~nm}\right]_{\mathrm{pH} 4.5},
\end{aligned}
$$

where TACY is the total anthocyanins expressed as mg cyanidin-3-glucoside/100 g DF fruit, MW is the molecular weight of cyaniding-3-glucoside $\left(449.2 \mathrm{~g} \mathrm{~mol}^{-1}\right)$, DF is the dilution factor, $\varepsilon$ is the molar absorbance coefficient of cyaniding-3-glucoside $\left(26,900 \mathrm{M}^{-1} \mathrm{~cm}^{-1}\right)$, and 0.1 is the conversion factor per $1000 \mathrm{~g}$ to $100 \mathrm{~g}$ basis. 


\section{Determination of Antioxidant Activity}

4.1. DPPH Radical Scavenging Assay. Radical scavenging activity of Crataegus fruits extracts against 2,2-diphenyl-1picrylhydrazyl (DPPH) radical was determined spectrophotometrically. The method first introduced by Blois [11], developed by Brand-Williams et al. [12], and criticized by Molyneux [13] was employed. The principle of the assay is based on the color change of the DPPH solution from purple to yellow as the radical is quenched by the antioxidant. Briefly, $100 \mu \mathrm{L}$ of methanol hawthorn fruits extract was added to $1.9 \mathrm{~mL}$ of $410-3 \mathrm{mM}$ of DPPH in methanol up to completing $2 \mathrm{~mL}$. The free radical scavenging capacity using the free $\mathrm{DPPH}$ radical was evaluated by measuring the decrease of absorbance at $517 \mathrm{~nm}$ every $2 \mathrm{~min}$ until the reaction reached its state. Additional dilution was needed if the DPPH value measured was over the linear range of the standard curve. The inhibition activity I(\%) was calculated as follows:

$$
I(\%)=100 \times \frac{\left(A_{0}-A_{1}\right)}{A_{0}},
$$

where $A_{0}$ is the absorbance of the control sample and $A_{1}$ is the absorbance of the test compound.

Extract concentration providing 50\% inhibition $\left(\mathrm{IC}_{50}\right)$ was calculated from the graph plotting inhibition percentage against extract concentration.

4.2. Ferric-Reducing/Antioxidant Power (FRAP). The procedure of FRAP assay was according to Benzie and Strain [14]. The principle of this method is based on the reduction of a ferric-tripyridyltriazine complex to its ferrous, colored form in presence of antioxidants. Briefly, the FRAP reagent contained $2.5 \mathrm{~mL}$ of $10 \mathrm{mmol} \mathrm{L}^{-1}$ TPTZ (2,4,6-tripyridyl-striazine, Sigma) solution in $40 \mathrm{mmol} \mathrm{L}^{-1} \mathrm{HCl}$ plus $2.5 \mathrm{~mL}$ of $20 \mathrm{mmol} \mathrm{L}^{-1} \mathrm{FeCl}_{3}$ and $25 \mathrm{~mL}$ of $0.3 \mathrm{~mol} \mathrm{~L}^{-1}$ acetate buffer, $\mathrm{pH} 3.6$, and was prepared freshly and warmed at $37^{\circ} \mathrm{C}$. Aliquots of $40 \mu \mathrm{L}$ sample supernatant were mixed with $0.2 \mathrm{~mL}$ distilled water and $1.8 \mathrm{~mL}$ FRAP reagent. The absorbance of reaction mixture at $593 \mathrm{~nm}$ was measured spectrophotometrically after incubation at $37^{\circ} \mathrm{C}$ for $10 \mathrm{~min}$ in a microplate (PowerWave XS, BioTek). The $1 \mathrm{mmol} \mathrm{L}^{-1}$ $\mathrm{FeSO}_{4}$ was used as the standard solution. The final result was expressed as the concentration of antioxidants having a ferric reducing ability equivalent to that of $1 \mathrm{mmol} \mathrm{L}^{-1} \mathrm{FeSO}_{4}$. Adequate dilution was needed if the FRAP value measured was over the linear range of standard curve.

4.3. $\beta$-Carotene/Linoleic Acid Assay. The antioxidant activity of extracts was evaluated using $\beta$-carotene/linoleic acid system according to the modified literature procedure $[15,16]$. A stock solution of $\beta$-carotene/linoleic acid (Sigma-Aldrich) was prepared as follows: first, $0.5 \mathrm{mg}$ of $\beta$-carotene was dissolved in $1 \mathrm{~mL}$ of chloroform (HPLC grade); then $25 \mu \mathrm{L}$ of linoleic acid and $200 \mathrm{mg}$ of Tween 40 (Merck) were added. The chloroform was subsequently evaporated using a vacuum evaporator (Buchi, Flawil, Switzerland). Then, $100 \mathrm{~mL}$ of distilled water saturated with oxygen $(30 \mathrm{~min}$ at $100 \mathrm{~mL} / \mathrm{min}$ ) was added with vigorous shaking. Aliquots $(2.5 \mathrm{~mL})$ of this reaction mixture were transferred to test tubes, and $350 \mu \mathrm{L}$ portions of the extracts $(2 \mathrm{~g} / \mathrm{L}$ in ethanol) were added before incubating for $48 \mathrm{~h}$ at room temperature. The same procedure was repeated with $\mathrm{BHT}$ at the same concentration and a blank containing only $350 \mu \mathrm{L}$ of ethanol. After the incubation period, absorbance of the mixtures was measured at $490 \mathrm{~nm}$. Antioxidant capacities of the samples were compared with those of BHT and of the blank.

\section{Results and Discussion}

5.1. Total Phenolic Contents. The level of phenolic compounds in methanolic aqua acidified extracts measured according to the Folin-Ciocalteu method of peel, pulp, and seed of Crataegus varieties is presented in Table 1. All parts of red and yellow Crataegus varieties were a significant source of polyphenols; however, the total amount varied significantly between 45.7 and $123.35 \mathrm{mg}$ gallic acid/100 g DW in the red variety and from 36.3 to $71.24 \mathrm{mg}$ gallic acid/100 g DW in yellow fruit. The red peel had the highest amount of total polyphenols (123.35 mg gallic acid/100 g DW) whereas seed of yellow fruit had the lowest amount. Referring to Table 1, in both varieties, total flavonoid contents in peel extract were more than in pulp, followed by seed. Comparing the varieties, it was found that all different parts of Crataegus monogyna had higher contents of flavonoids (198.53 mg eq. rutin $/ 100 \mathrm{gDW})$ in peel followed by $(160.35 \mathrm{mg}$ eq. rutin/100 g DW) in pulp and (96.01 $\mathrm{mg}$ eq. rutin/100 $\mathrm{g} \mathrm{DW}$ ) in seed; however, peel, pulp, and seed of Crataegus azarolus had the lowest TF (155.40, 60.45, and $14.71 \mathrm{mg}$ eq. rutin/100 g DW, resp.). Findings also established the main source of total phenolics and total flavonoids in Crataegus monogyna to be the peel, which were about $123.35 \mathrm{mg}$ gallic $\mathrm{acid} / 100 \mathrm{~g} \mathrm{DW}$ and $198.53 \mathrm{mg}$ eq. rutin/100 g DW. The results of the present study indicated consistently the lowest values of total anthocyanins contents in the both varieties when compared to the other bioactive compounds. The red fruit contained higher amounts (5.85 mg eq. cyanidin/100 g DW) in peel and (0.31 mg eq. cyanidin/100 g DW) in fruit; however, yellow fruits are poured in anthocyanins. Proanthocyanidins or condensed tannins are ubiquitous and present as the second most abundant natural phenolics. The proanthocyanidins have been suggested to contribute to the phenomenon called health promoting effects, such as antioxidant, anticarcinogenic, and anti-inflammatory effects $[17,18]$. According to Table 1, flavon-3-ols are the most abundant compounds present in Crataegus fruits; they represent more than half of the other compounds. Total proanthocyanidins content is most abundant in the red peel $(873.58 \mathrm{mg}$ eq. cyanidin/100 g DW), and a lower level was found in the yellow fruits ( $97.06 \mathrm{mg}$ eq. cyanidin/100 g DW). We show that total antioxidants contents are influenced by the species of Crataegus and the different parts of fruit in the same variety, both peels were the rich source of antioxidant compounds.

5.2. Antioxidant Activities. In the present study, the antioxidant activities of Crataegus determined by free radical scavenging activity (DPPH) assay method indicated a steady 
TABLE 1: Phenolics contents in different crude part extracts of red and yellow Crataegus.

\begin{tabular}{|c|c|c|c|c|}
\hline \multicolumn{5}{|c|}{ Source of extract } \\
\hline & Variety & Peel & Pulp & Seed \\
\hline \multirow{2}{*}{ Total phenolics ${ }^{\mathrm{a}}$} & C. monogyna & $123.35 \pm 0.02$ & $122.26 \pm 0.16$ & $45.72 \pm 0.04$ \\
\hline & C. azarolus & $71.24 \pm 0.01$ & $60.89 \pm 0.04$ & $36.03 \pm 0.02$ \\
\hline \multirow{2}{*}{ Total flavonoids ${ }^{\mathrm{b}}$} & C. monogyna & $198.53 \pm 0.11$ & $160.35 \pm 0.1$ & $96.01 \pm 0.01$ \\
\hline & C. azarolus & $155.40 \pm 0.23$ & $60.45 \pm 0.06$ & $14.71 \pm 0.02$ \\
\hline \multirow{2}{*}{ Proanthocyanidins ${ }^{c}$} & C. monogyna & $873.58 \pm 0.33$ & $507.31 \pm 0.32$ & $399.68 \pm 0.29$ \\
\hline & C. azarolus & $352.91 \pm 0.29$ & $291.16 \pm 0.19$ & $97.06 \pm 0.21$ \\
\hline \multirow{2}{*}{ Total anthocyanins ${ }^{\mathrm{d}}$} & C. monogyna & $5.58 \pm 0.05$ & $0.31 \pm 0.03$ & 0 \\
\hline & C. azarolus & 0 & 0 & 0 \\
\hline
\end{tabular}

${ }^{\text {a } T o t a l ~ p h e n o l: ~ F o l i n-C i o c a l t e u, ~ i n ~ m g ~ e q . ~ g a l l i c ~ a c i d / 100 ~ g ~ D W . ~}$

${ }^{\mathrm{b}}$ Flavonoids: $\mathrm{AlCl}_{3}$ method, in mg eq. rutin/100 g DW.

${ }^{c}$ Anthocyanins: direct colorimetry in mg eq. cyanidin-3-O-glucoside/100 g DW.

${ }^{\mathrm{d}}$ Procyanidins: butanol- $\mathrm{HCl}$ methods, in mg eq. cyanidins/100 g DW.

TABLE 2: Free radical scavenging capacity, FRAP assay, and standard antioxidants of Crataegus fruit extract.

\begin{tabular}{|c|c|c|c|c|}
\hline & & $\mathrm{DPPH} \mathrm{IC}_{50}(\mu \mathrm{g} / \mathrm{mL})$ & FRAP (mM Trolox) & FRAP (mM AA) \\
\hline \multirow{3}{*}{ C. monogyna } & Peel & 750 & 8.88 & 9.12 \\
\hline & Pulp & 720 & 5.44 & 5.68 \\
\hline & Seed & 540 & 5.71 & 5.95 \\
\hline \multirow{3}{*}{ C. azarolus } & Peel & 780 & 6.89 & 7.13 \\
\hline & Pulp & 560 & 4.40 & 4.64 \\
\hline & Seed & 240 & 6.15 & 6.39 \\
\hline Control & BHT & 820 & - & - \\
\hline
\end{tabular}

increase in the scavenging activity of free radicals in all extracts and standard range between 240 and $800 \mu \mathrm{g} / \mathrm{mL}$ (Table 2). It was observed that the ability of test materials (pure antioxidants and fruits extracts) to scavenge DPPH was assessed on the bases of their $\mathrm{IC}_{50}$ values, defined above as the concentration of test material to decrease the absorbance at $515 \mathrm{~nm}$ (or concentration) of DPPH solution to half of its initial value. These $\mathrm{IC}_{50}$ values of Crataegus fruit extract are given in Table 2. It can be seen that seed from yellow variety shows higher $\mathrm{IC}_{50}$ value $(780 \mu \mathrm{g} / \mathrm{mL})$ than red peel $(750 \mu \mathrm{g} / \mathrm{mL})$. This result can be attributed to the higher phenolic content of the peel and pulp. The higher DPPH radical scavenging activity is associated with a lower $\mathrm{IC}_{50}$. FRAP values of peel, pulp, and seed fractions of Crataegus fruits are also summarized in Table 2. The reducing ability of different parts of red Crataegus fruits extracts is expressed, respectively, in $\mathrm{mM}$ Trolox equivalent and $\mathrm{mM}$ ascorbic acid equivalent: they ranged from $5.44-8.88 \mathrm{mM}$ Trolox/100 g DW to $5.68-9.12 \mathrm{mM}$ ascorbic acid/100 g DW. These values are more important than the reducing ability of yellow fruits; however, they ranged from 4.64 to $7.13 \mathrm{mM}$ Trolox/100 g DW and, 4.4 to $6.89 \mathrm{mM} \mathrm{A} \mathrm{A/100} \mathrm{g} \mathrm{DW.} \mathrm{The}$ decreasing order efficiency in FRAP system is as follows: peel $>$ pulp > seed in both varieties of Crataegus fruits extract. These results agreed with the DPPH values. The basis of $\beta$-carotene/linoleic acid assay is discoloration of $\beta$-carotene in reaction with linoleic acid free radical. That radical is formed at elevated temperature upon removal of hydrogen atom located between two double bonds of linoleic acid [16].

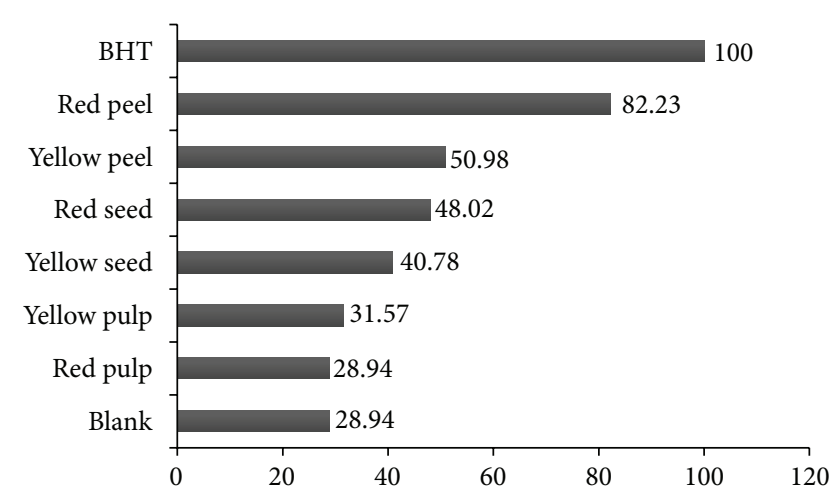

FIgURE 1: Relative antioxidant activity of Crataegus extracts and positive control (BHT) in $\beta$-carotene/linoleic acid assay.

The consequence is the loss of conjugation and, accordingly, a decrease in absorbance at $470 \mathrm{~nm}$. Antioxidants present in solution can prevent the degradation of $\beta$-carotene by reacting with the linoleate free radical or any other radical formed in the solution.

The reduction in absorbance of $\beta$-carotene-linoleate emulsion in presence of the extracts is shown in Figure 1. Relative antioxidant activity of Crataegus extracts increased with the species and the parts of fruits. In the $\beta$-carotene/linoleic acid model system, we could conclude that results were consistent with the data obtained from DPPH test and FRAP assay. Peel extract of red fruit showed markedly relative 
TABLE 3: Linear correlation of Trolox equivalent antioxidant capacity (TEAC) versus the total phenolic content of crataegus fruit extract.

\begin{tabular}{|c|c|c|c|}
\hline \multirow{2}{*}{ Variety } & \multirow{2}{*}{ Phenolic contents } & \multicolumn{2}{|c|}{ Correlation coefficients } \\
\hline & & $\mathrm{TEAC}_{\mathrm{DPPH}}$ & TEAC $_{\text {FRAP }}$ \\
\hline \multirow{3}{*}{ C. monogyna } & $\mathrm{TP}$ & $\begin{array}{c}y=2.5328 x+424.06 \\
R^{2}=0.9856\end{array}$ & $\begin{array}{c}y=0.0245 x+4.2986 \\
R^{2}=0.3249\end{array}$ \\
\hline & $\mathrm{TF}$ & $\begin{array}{c}y=2.1267 x+347.53 \\
R^{2}=0.9412\end{array}$ & $\begin{array}{c}y=0.0305 x+2.054 \\
R^{2}=0.6819\end{array}$ \\
\hline & $\mathrm{PC}$ & $\begin{array}{c}y=0.3507 x+461.84 \\
R^{2}=0.5885\end{array}$ & $\begin{array}{c}y=0.0076 x+2.1564 \\
R^{2}=0.9783\end{array}$ \\
\hline \multirow{3}{*}{ C. azarolus } & $\mathrm{TP}$ & $\begin{array}{c}y=14.884 x-307.64 \\
R^{2}=0.983\end{array}$ & $\begin{array}{c}y=0.0707 x+1.8527 \\
R^{2}=1\end{array}$ \\
\hline & $\mathrm{TF}$ & $\begin{array}{c}y=3.6082 x+249.36 \\
R^{2}=0.9094\end{array}$ & $\begin{array}{c}y=0.0162 x+4.5682 \\
R^{2}=0.8267\end{array}$ \\
\hline & $\mathrm{PC}$ & $\begin{array}{c}y=1.9996 x+32.668 \\
R^{2}=0.9666\end{array}$ & $\begin{array}{c}y=0.0096 x+3.4515 \\
R^{2}=0.9964\end{array}$ \\
\hline
\end{tabular}

TP: Total polyphenols.

TF: Total flavonoids.

PC: Proanthocyanidin content.

antioxidant activity (82.23\%), as did the peel extract of yellow fruit (50.98\%). These results implied that the potential antioxidant capabilities in Crataegus monogyna were attributed to the phenolic compounds in this species compared with Crataegus azarolus species. Pulp of yellow fruit showed the weakest activity potential in this test system (28.24\%) (Table 3).

5.3. Relationships amongst Different Antioxidants. Free radical scavenging of phenolic compounds is an important property underlying their various biological and pharmacological activities. Recently, Awika et al. [19] found positive correlations between the determinations of phenolic antioxidant using the oxygen radical absorbance capacitys (ORAC), ABTS, and DPPH assays. Results revealed that polyphenols from Crataegus fruit extract had high antioxidant activities (Table 1). The total phenolic compounds contents were also highly correlated with the antioxidant activities with the DPPH method and the FRAP assay. Data of the correlations $\left(R^{2}\right)$ summarized in Table 2 with total polyphenols content in red fruits were $0.98,0.94$, and 0.58 , respectively. $\mathrm{DPPH}$ was also highly correlated with TP, TF, and PC of red fruit; the data show $0.98,0.90$, and 0.96 , respectively. The correlation between Trolox equivalent antioxidant capacity (TEAC) $(Y)$ and total phenolic contents $(X)$ of Crataegus monogyna had a coefficient $\left(R^{2}\right)$ varied from 0.32 to 0.97 while the correlation coefficient of Crataegus azarolus are 1, 0.99 and 0.82 (Table 1). This result suggests that higher percentage of the antioxidant capacity of Tunisia Crataegus accessions results from the contribution of phenolic compounds. Also, it can be concluded that antioxidant activity of plant extracts is not limited to phenolics content but also comes from the presence of other antioxidant secondary metabolites, such as flavonoids, proanthocyanidins, and anthocyanins. The antioxidant activity of phenolics is mainly due to their redox properties, which allow them to act as reducing agents, hydrogen donors, and singlet oxygen quenchers.
They may also have a metal chelating potential [20]. Besides flavoring purposes, spices and herbs have also been used for their medical or antiseptic properties because of their richness in bioactive molecules and consequently their benefits for human health [21].

\section{Conclusion}

Comparison of phenolic contents and antioxidant activities of methanol extracts of Crataegus azarolus and Crataegus monogyna fruits cultivated in Tunisia shows the presence of total phenols, proanthocyanidins, and flavonoids with some difference. Anthocyanins are present only in red fruit. This richness in antioxidants contributes to the antioxidative effect. A linear correlation of Trolox equivalent antioxidant capacity (TEAC) versus the total phenolic content of Crataegus was established. The richest composition in antioxidant compounds and the higher antioxidant capacity activity of Crataegus can improve the use of these fruits in various fields such as agroalimentary and pharmaceutical industry.

\section{Acknowledgment}

The authors would like to acknowledge the Tunisian Ministry of Higher Education for the scholarship.

\section{References}

[1] E. Haslam, "Natural polyphenols (vegetable tannins) as drugs: possible modes of action," Journal of Natural Products, vol. 59, no. 2, pp. 205-215, 1996.

[2] A. J. Parr and G. P. Bolwell, "Phenols in the plant and in man. The potential for possible nutritional enhancement of the diet by modifying the phenols content or profile," Journal of the Science of Food and Agriculture, vol. 80, pp. 985-1012, 2000.

[3] Y. S. Velioglu, G. Mazza, L. Gao, and B. D. Oomah, "Antioxidant activity and total phenolics in selected fruits, vegetables, and 
grain products," Journal of Agricultural and Food Chemistry, vol. 46, no. 10, pp. 4113-4117, 1998.

[4] T. Osawa, "Novel natural antioxidants for utilization in food and biological systems," in Postharvest Biochemistry of Plant Food-Materials in the Tropics, I. Uritani, V. V. Garcia, and E. M. Mendoza, Eds., pp. 241-251, Japan Scientific Societies Press, 1994.

[5] S. Khanizadeh, R. Tsao, D. Rekika, R. Yang, M. T. Charles, and H. P. Vasantha Rupasinghe, "Polyphenol composition and total antioxidant capacity of selected apple genotypes for processing," Journal of Food Composition and Analysis, vol. 21, no. 5, pp. 396401, 2008.

[6] V. L. Singleton and J. A. Rossi Jr., "Colorimetry of total phenolics with phosphomolybdic-phosphotungstic acid reagents," Americain Journal of Enology and Viticulture, vol. 16, no. 3, pp. 144-158, 1965.

[7] J. Zhishen, T. Mengcheng, and W. Jianming, "The determination of flavonoid contents in mulberry and their scavenging effects on superoxide radicals," Food Chemistry, vol. 64, no. 4, pp. 555$559,1999$.

[8] J. L. Lamaison and A. Carnat, "Teneurs en principaux flavonoïdes des fleurs et des feuilles de Crataegus monogyna Jacq. et de Crataegus laevigata (Poiret) DC. En fonction de la période de végétation," Plantes Médicinales et Phytothérapie, vol. 25, no. 1, pp. 12-16, 1991.

[9] L. J. Porter, L. N. Hrstich, and B. G. Chan, "The conversion of procyanidins and prodelphinidins to cyanidin and delphinidin," Phytochemistry, vol. 25, no. 1, pp. 223-230, 1985.

[10] M. M. Giusti and R. E. Wrolstad, "Unit F1. 2: anthocyanins. Characterization and measurement with UV-visible spectroscopy," in Current Protocols in Food Analytical Chemistry, R. E. Wrolstad, Ed., pp. 1-13, John Wiley \& Sons, New York, NY, USA, 2001.

[11] M. S. Blois, "Antioxidant determinations by the use of a stable free radical," Nature, vol. 181, no. 4617, pp. 1199-1200, 1958.

[12] W. Brand-Williams, M. E. Cuvelier, and C. Berset, "Use of a free radical method to evaluate antioxidant activity," Food Science and Technology-Lebensmittel-Wissenschaft and Technologie, vol. 28, no. 1, pp. 25-30, 1995.

[13] P. Molyneux, "The use of the stable free radical diphenylpicrylhydrazyl (DPPH) for estimating antioxidant activity. Songklanakarin," Journal of Science and Technology, vol. 26, pp. 211219, 2004.

[14] I. F. F. Benzie and J. J. Strain, "The ferric reducing ability of plasma (FRAP) as a measure of "antioxidant power": The FRAP assay," Analytical Biochemistry, vol. 239, no. 1, pp. 70-76, 1996.

[15] H. E. Miller, "A simplified method for the evaluation of antioxidants," Journal of American Oil Chemistry Society, vol. 48, no. 2, p. 91, 1971.

[16] R. Amarowicz, R. B. Pegg, P. Rahimi-Moghaddam, B. Barl, and J. A. Weil, "Free-radical scavenging capacity and antioxidant activity of selected plant species from the Canadian prairies," Food Chemistry, vol. 84, no. 4, pp. 551-562, 2004.

[17] C. Santos-Buelga and A. Scalbert, "Proanthocyanidins and tanninlike compounds-nature, occurrence, dietary intake, and effects on nutrition and health," Journal of the Science of Food and Agriculture, vol. 80, pp. 1094-1117, 2000.

[18] S. Carnésecchi, Y. Schneider, S. A. Lazarus, D. Coehlo, F. Gossé, and F. Raul, "Flavanols and procyanidins of cocoa and chocolate inhibit growth and polyamine biosynthesis of human colonic cancer cells," Cancer Letters, vol. 175, no. 2, pp. 147-155, 2002.
[19] J. M. Awika, L. W. Rooney, X. Wu, R. L. Prior, and L. CisnerosZevallos, "Screening methods to measure antioxidant activity of sorghum (Sorghum bicolor) and sorghum products," Journal of Agricultural and Food Chemistry, vol. 51, no. 23, pp. 6657-6662, 2003.

[20] C. A. Rice-Evans, N. J. Miller, P. G. Bolwell, P. M. Bramley, and J. B. Pridham, "The relative antioxidant activities of plant-derived polyphenolic flavonoids," Free Radical Research, vol. 22, no. 4, pp. 375-383, 1995.

[21] M. P. Kähkönen, A. I. Hopia, H. J. Vuorela et al., "Antioxidant activity of plant extracts containing phenolic compounds," Journal of Agricultural and Food Chemistry, vol. 47, no. 10, pp. 3954-3962, 1999. 

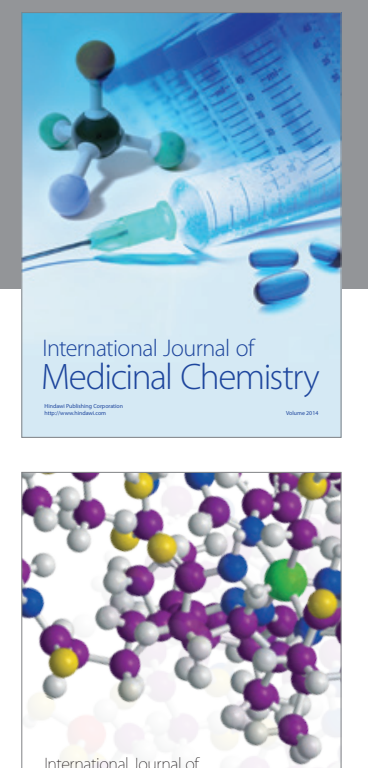

\section{Carbohydrate} Chemistry

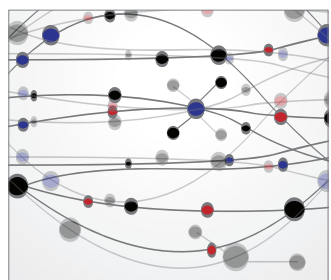

The Scientific World Journal
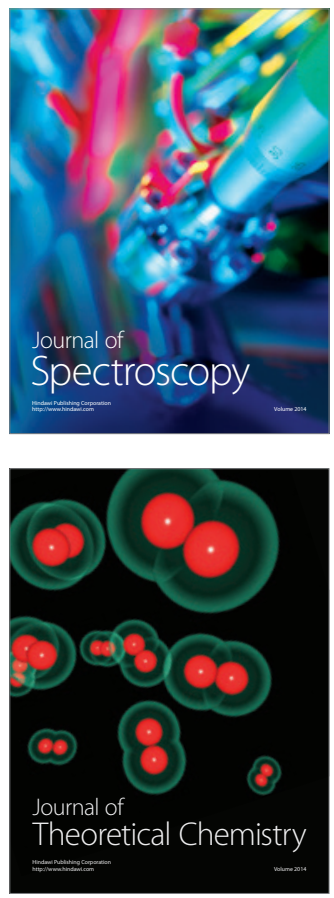
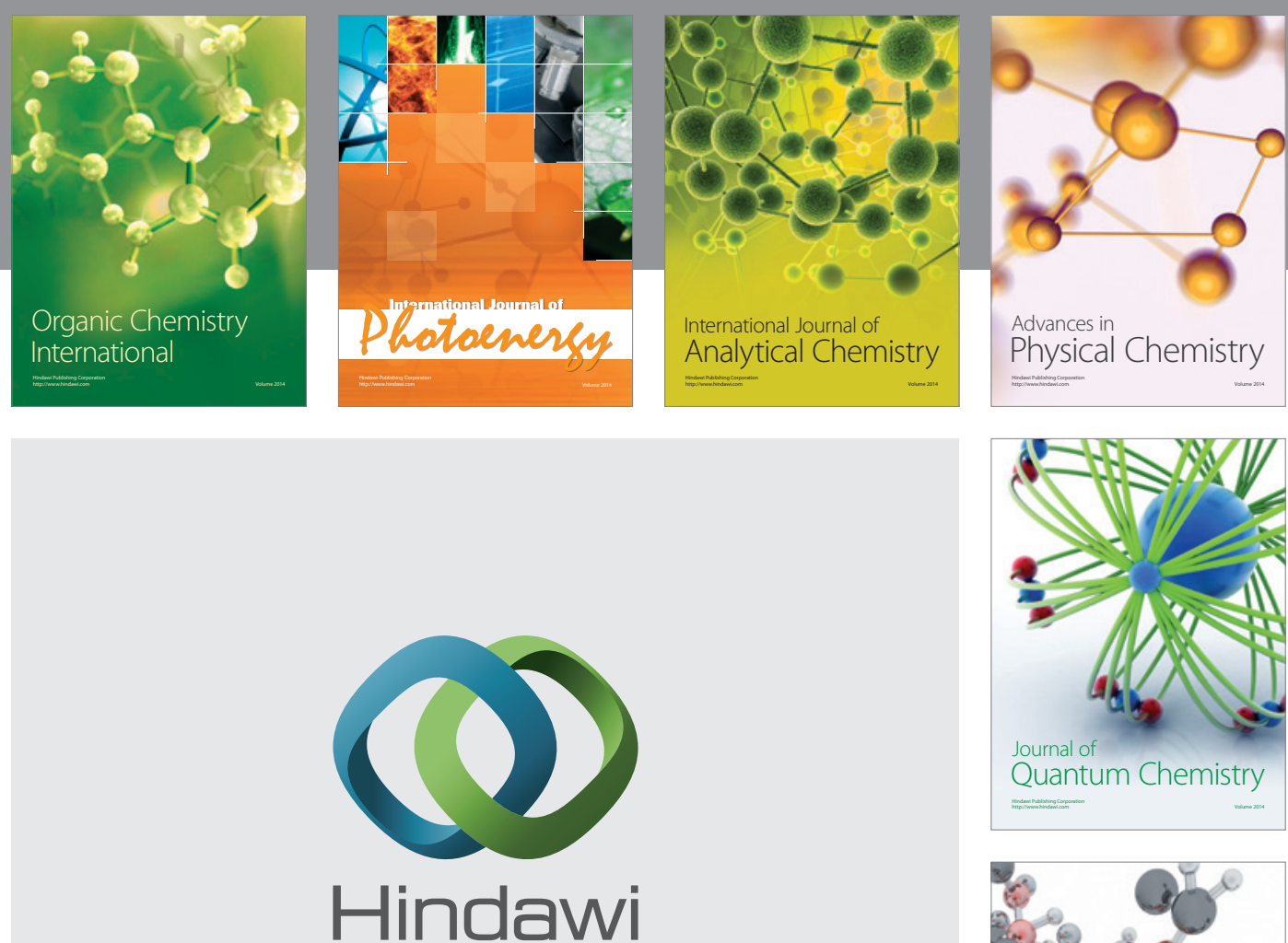

Submit your manuscripts at

http://www.hindawi.com

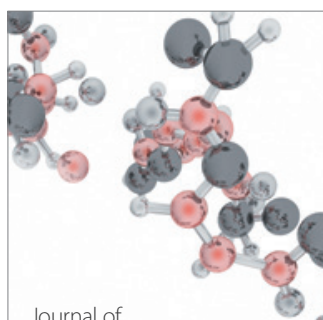

Analytical Methods

in Chemistry

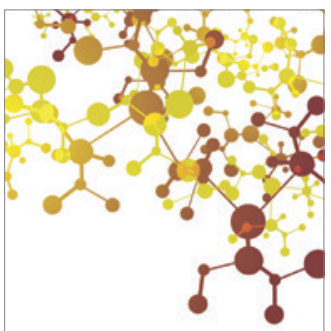

Journal of

Applied Chemistry

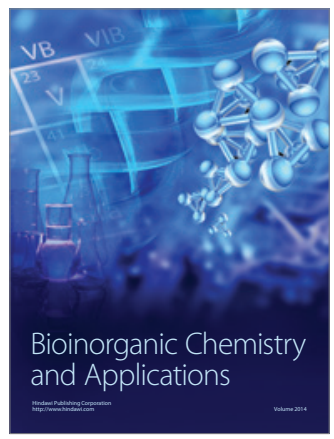

Inorganic Chemistry
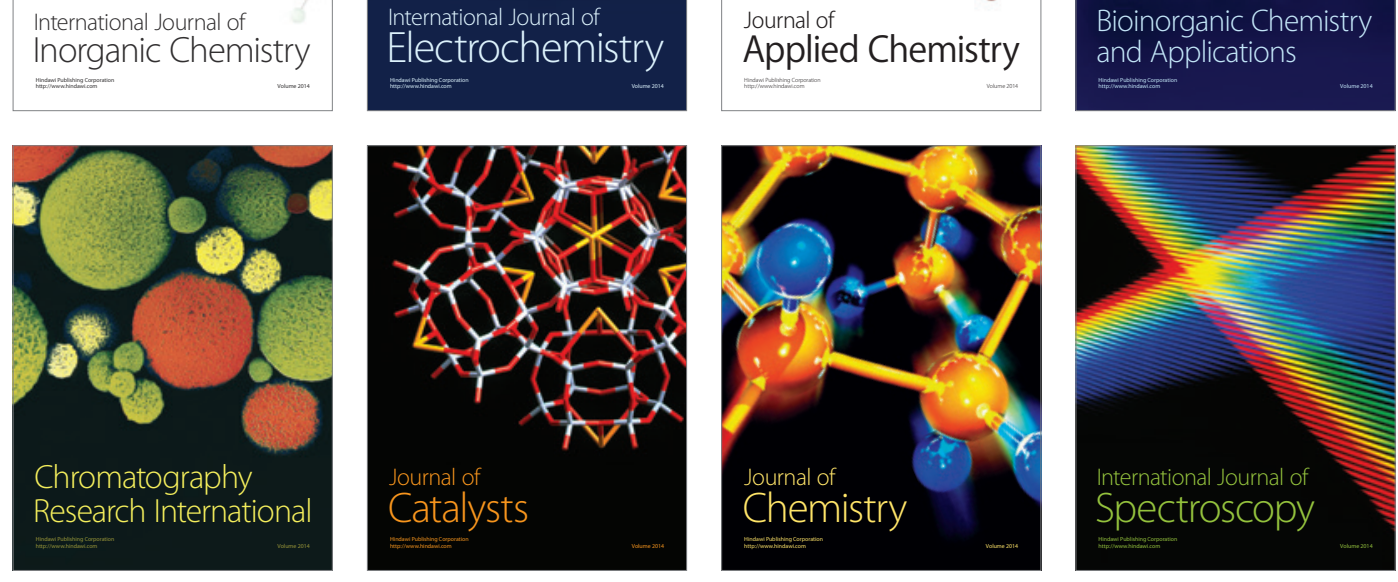